\title{
Characteristics of the Central Nervous System Malformations Presented in Trisomy 13: A single-center Experience in Recognizing the Phenotype and Genotype
}

\author{
Ahmad Faried ${ }^{1,2 \star}$, Bremmy Laksono ${ }^{2}$, Danny Halim${ }^{1}$, Riksa Parikrama ${ }^{2}$, Mirna Sobana ${ }^{1}$, Muhammad Z. Arifin $^{1}$ \\ ${ }^{1}$ Department of Neurosurgery, Faculty of Medicine, Padjadjaran University (UNPAD), Dr. Hasan Sadikin Hospital (RSHS), \\ Bandung, Indonesia; ${ }^{2}$ The Center of Genetic Study, Faculty of Medicine, Universitas Padjadjaran, Bandung, Indonesia
}

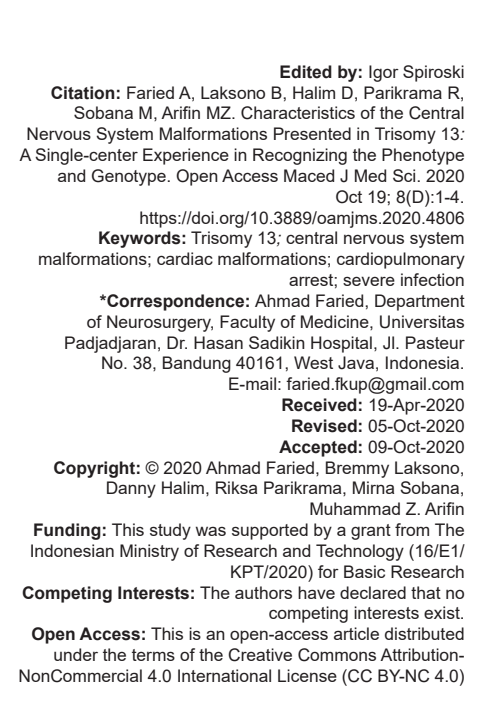

Abstract

BACKGROUND: Patients who are diagnosed with trisomy 13 (Patau syndrome) are known to have a poor prognosis. It has been hypothesized that such poor outcomes are suspected to be attributed to their central nervous system (CNS)-malformations and cardiac-malformations. This study was conducted at Division of Neuropediatric, Department of Neurosurgery, Faculty of Medicine, Universitas Padjadjaran - Dr. Hasan Sadikin Hospital, Bandung (2012-2018).

AIM: This study aimed to describe clinical characteristics and karyotype findings in patients who were diagnosed with Patau syndrome and treated at our center. Since Indonesia is still categorized as a lower middle-income country with limited resources, we expected that this study would provide a clinical reference on how a congenital disease with chromosomal abnormalities is confirmed.

CASE PRESENTATION: Our cases indicate that CNS malformations are likely to be the cause of indirect mortality of patients' early period of life. The median survival in our study is 7 days, while the longest survival is 30 days. The major cause of death is apnea, which found in 4 of 5 diagnosed infants. One patient died of severe infection. In most cases, where CNS malformations were observed microcephaly with sloping forehead, Dandy-Walker syndrome, lobar or alobar holoprosencephaly and ventriculomegaly were identified, as well as neural tube defects (NTDs) were identified such as spina bifida and meningoencephalocele. CNS malformations, such as holoprosencephaly, may be associated with episodes characterized by temporary cessation of spontaneous breathing (apnea) as direct cause of mortality.

CONCLUSION: We conclude that early treatment in Patau syndrome patient in our center should be focused on more life-threatening problem caused by CNS malformations than NTDs defects, such defects could be managed electively.

\section{Introduction}

Patau syndrome is an incurable congenital disease, characterized by malformation of body parts, and impaired intellectual capacities. In the majority of the cases, karyotyping identifies trisomy of chromosome 13. However, a duplication of part(s) of chromosome 13 and mosaicism has also been acknowledged in some patients, thus resulting in the diversity of phenotypes of Patau syndrome. Therefore, it is not surprising if phenotype and karyotype findings in patients who are diagnosed with Patau syndrome have kept scientists and clinicians intrigued. In lower- to middle-income countries like Indonesia, diagnosis and treatment of congenital diseases such as Patau syndrome are still challenging. Apart from difficulties such as the unavailability of a medical specialist in clinical genetics and the overwhelming number of patients treated with related specialists on a daily basis, limited resources added another layer of challenges in making diagnosis and treating patients with Patau syndrome. This is how we describe our experiences in establishing diagnosis of patients with Patau syndrome. To the best of our knowledge, there is no preceding report regarding the clinical characteristics, and karyotype findings in Indonesia, especially in Bandung have ever been released. The aim of this study is to provide an insight regarding the management of Patau syndrome from the case series of Patau syndrome at our center. The correlation of trisomy 13 to this syndrome was first described by Patau et al. in 1960 [1]. Most infants with Patau syndrome have a high mortality; the median survival around 4 days old [2]. Malformations of the central nervous system (CNS) and cardiac have been suggested as main attribute of death caused in patients with Patau syndrome. A thorough study on the clinical characteristics would also be useful to evaluate the true cause of death among patients who are diagnosed with Patau syndrome, particularly in patients who were diagnosed and treated at our center. 


\section{Case Presentation}

This is a case series study performed in a single center: Faculty of Medicine, Universitas Padjadjaran (FK UNPAD) - Dr. Hasan Sadikin Hospital (RSHS), Bandung. Patients suspected of having Patau syndrome were initially admitted to the department of pediatrics or neurology before being consulted to the department of neurosurgery. When necessary, the diagnosis was confirmed the cytogenetic examination. Data were collected from patients who were suspected of having Patau syndrome, in the period of 20122018. The inclusion criteria were patients with clinical phenotype of Patau syndrome and having been confirmed of having trisomy of chromosome 13. Since karyotyping is not covered by our national insurance coverage, not all patients who were suspected with Patau syndrome could be included in this study. They were around 15 patients suspected with Patau syndrome, which was admitted during the study period; most clinical examinations reveal as microcephaly, cleft lip and palate, and low set ears. Clinical characteristics and karyotype findings were constructed from patients' medical record.

Five patients with Patau syndrome who had their diagnosis confirmed at the period of 2012 to 2018 were included in this study (Table 1):

Patient \#1. was born a term from P2A1 mother (37-38 weeks of gestation), with multiple congenital anomaly (posterior meningioencephalocele rupture, microcephaly, right microphtalmia, immature retina at the left eye, short neck, labiopalatoschisis, and low set ear); karyotype as $47, \mathrm{XY},+13$ (Figure 1), and imaging evaluations shown a dextrocardia, right lung dysgenesis, and spina bifida at the corpus of thoracic vertebra 1, 2, and 3; open wound care as treatment for meningioencephalocele rupture with antibiotics therapy for infection occurred and respiratory failure complications (Figure 2) treated in neonatology intensive care unit with poor prognosis; and apnea as cause of death.

Patient \#2. was born a term from P1A0 mother (37-38 weeks of gestation); with multiple congenital anomaly (microcephaly with sloping forehead, widely set eyes, labiopalatoschisis, omphalocele); karyotype as $47, \mathrm{XX},+13$, and imaging evaluations shown polydactyl; complications from sepsis neonatorum treated in neonatology intensive care unit with poor prognosis; and severe infection as cause of death.

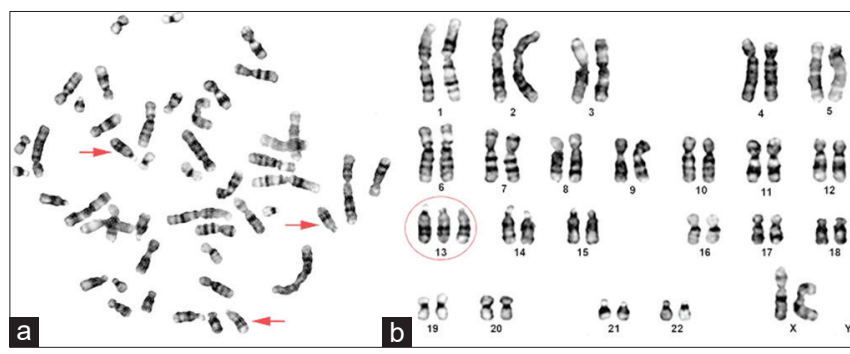

Figure 1: Representative results of karyotyping of Trisomy 13. Chromosomes images obtained from cover slide glass, with three sets of chromosome 13 are shown with arrows (a). Reported rearrangement of the total chromosomes showed that the patient has a total of 47 chromosomes, including three complete copies of chromosome 13 shown in the red circle (b)

Patient \#3. was born a term from P1A0 mother (37-38 weeks of gestation), with Dandy-Walker syndrome and seizure; karyotype as $47, \mathrm{XY},+13$, and imaging evaluations shown hypoplasia of the vermis, cystic dilatation of the fourth ventricle, and enlarged posterior fossa with torcular-lambdoid inversion; respiratory failure complications treated in neonatology intensive care unit with poor prognosis; and apnea as cause of death.



Figure 2: Identified clinical features showed sloping forehead microcephaly, a broad flat nose, widely set eyes with posterior meningioencephalocele rupture, right microphtalmia, absent of eyebrows (white arrow), immature retina at the left eye, short neck, labiopalatoschisis, abnormal low set of ears (red circle) (a). Radiological feature showing dextrocardia, right lung dysgenesis, unclear renal contour and spina bifida of corpus vertebra thoracal 1,2,3 (b)

Patient \#4. was born aterm from P5A2 mother (38 weeks of gestation), with microcephaly, microphthalmia, labiopalatoschisis, and low set ears; karyotype as $47, \mathrm{XX},+13$, and imaging evaluations shown lobar holoprosencephaly (Figure 3) and ventriculomegaly; respiratory failure complications treated in neonatology intensive care unit with poor prognosis; and apnea as cause of death.

Patient \#5. was born premature from P3A1 mother (35 weeks of gestation), with microcephaly with

Table 1: Clinical characteristics of five patients who were diagnosed with trisomy 13; phenotypes findings was shown below

\begin{tabular}{|c|c|c|c|c|c|}
\hline No. & Gender & $\begin{array}{ll}\text { Year } \\
\text { admitted }\end{array}$ & $\begin{array}{l}\text { Age when } \\
\text { karyotyped (days) }\end{array}$ & $\begin{array}{l}\text { Survival rate } \\
\text { (days) }\end{array}$ & Clinical phenotypes \\
\hline$\overline{1}$ & Male & 2012 & 6 & 7 & $\begin{array}{l}\text { Posterior Meningioencephalocele Rupture + Multiple Congenital Anomaly (Microcephaly, Right Microphtalmia, Immature } \\
\text { Retina at the left eye, Short Neck, Labiopalatoschisis, Low Set Ear, Dextrocardia, Right Lung Dysgenesis, Spina Bifida at } \\
\text { the Corpus of Thoracic Vertebra 1,2,3), Respiratory Failure (cause of death: Apnea) }\end{array}$ \\
\hline 2 & Female & 2016 & 3 & 5 & $\begin{array}{l}\text { Microcephaly with sloping forehead, Widely Set Eyes, Labiopalatoschisis, Omphalocele, Polydactyl, Sepsis Neonatorum } \\
\text { (cause of death: Severe infection) }\end{array}$ \\
\hline 3 & Male & 2017 & 21 & 30 & Dandy-Walker Syndrome, Seizure, Respiratory Failure (cause of death: Apnea) \\
\hline 4 & Female & 2017 & 6 & 7 & $\begin{array}{l}\text { Microcephaly, Lobar Holoprosencephaly, Ventriculomegaly, Microphtalmia, Labiopalatoschisis, Low Set Ears, Respiratory } \\
\text { Failure (cause of death: Apnea) }\end{array}$ \\
\hline 5 & Male & 2018 & 2 & 3 & $\begin{array}{l}\text { Microcephaly with sloping forehead, Alobar Holoprosencephaly, Ventriculomegaly, Labiopalatoschisis, Ambiguous Genitalia, } \\
\text { Respiratory Failure (cause of death: Apnea) }\end{array}$ \\
\hline
\end{tabular}


sloping forehead, labiopalatoschisis, and ambiguous genitalia; karyotype results $47, \mathrm{XY},+13$, and imaging evaluations shown alobar holoprosencephaly (Figure 3) and ventriculomegaly; respiratory failure complications treated in neonatology intensive care unit with poor prognosis; and apnea as cause of death. Despite clinical managements, all patient-reported in our study died between 3 and 30 days after birth. The median survival age of our reported study was 7 days, and despite the presence of CNS-malformations and cardiac-malformations, the cause of death in four patients was cardiopulmonary arrest, while the severe infection was acknowledged in one patient.

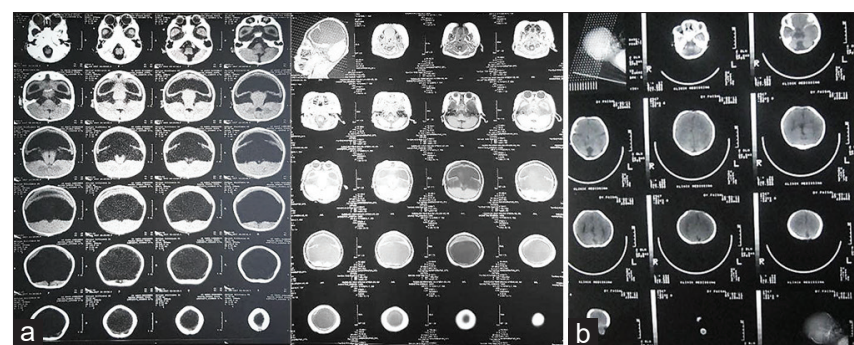

Figure 3: CT scan showedanomalisuch sloping foreheadmicrocephaly, alobar holoprosencephaly (a) or lobar holoprosencephaly (b) with ventriculomegaly and labiopalatoschisis

\section{Discussion}

Patau syndrome is a congenital disorder which is caused by non-disjunction of chromosome 13 during meiosis in 1 of the 2 gametes, resulting in complete or partial trisomy of chromosome 13. To date, Patau syndrome has a prevalence of 1:8000-12,000 live births [2], [3]. The phenotype of trisomy 13 patients may vary in accordance with the findings whether the chromosome defect is complete or partial and whether it occurs in all cells or in some cells (mosaicism). Severe malformations involving multiple organs, including microcephaly, cyclopia, abnormal nasal structures, cleft lip and palate, low set ears, cardiac defect, and polydactyly have been described, as clinical features found in trisomy 13 patients. Furthermore, it has also been associated with neural tube defects (NTDs), such as encephalocele, anencephaly, and spina bifida. In a study performed in 2000-2011 as population-based registries of 16 European countries, the prevalence of cardiac malformations was 57\% (51-64\%) and CNS malformations were $39 \%(33-46 \%)$. Boys were less likely to have CNS malformations than girls $(\mathrm{OR}=0.46$ [0.27-0.77]) [4].

Byrne and Warburton identified trisomy 13 in an aborted embryo with encephalocele [5]. A study by Seller discovered that $8 \%$ of patients with trisomy 13 had spina bifida [6]. Phadke and Thakur reported prenatal diagnosis of iniencephaly, alobar holoprosencephaly, and cyclopia in a fetus with mosaic trisomy 13 [7]. Halder et al. reported mosaic trisomy 13 in a fetus with iniencephaly, anencephaly, facial clefts, single umbilical artery, dilated right cardiac atrium, ventricle, and clubfoot [8]. Several studies have shown that NTDs are acquired in approximately $8 \%$ of trisomy 13 cases [2], [5], [9]. Rodriguez et al. revealed spina bifida in three out of 34 patients diagnosed with trisomy $13(8.8 \%) .{ }^{9}$ Wyllie et al. identified meningocele in one patient, while encephalocele in two patients, in among 36 patients, diagnosed with trisomy 13 (8.33\%) [2]. In our study, holoprosencephaly (lobar and alobar) with ventriculomegaly was identified in 2 live-born patients. All infants were presented with CNS malformations and died between 3 and 30 days of life. The cause of death in four out of five patients was recurrent apnea. Sepsis was found in the other patients whose apnea was not identified. Cyanosis was identified in three patients, which was attributed to the congenital heart defects and cardiopulmonary arrest. Medical examinations and nursing notes confirmed the presences of inadequate breathing in all patients.

In several studies, the median survival for liveborn children with trisomy 13 is $7-10$ days, about $90 \%$ die within the $1^{\text {st }}$ year, with the majority (approximately $80 \%$ ) dying within the $1^{\text {st }}$ month of life. However, longer survival is possible. There are published cases of patients with trisomy 13 who are over 5 years of age. Lower frequency of heart defects may contribute to the longer survival. In a Canadian cohort, the mean 1 -year survival was $19.8 \%$, and 10 -year survival was $12.9 \%$. Most deaths occurred in the first 3 months of life [10], [11], [12], [13]. When a routine head USG findings suspect the presence of trisomy 13 in a fetus, confirmation of the diagnosis of trisomy 13 can be acquired by prenatal genetic screening. Until now, there is no specific therapy or treatment for patients with trisomy 13. Thus, the prognosis of infants with trisomy 13 is extremely poor, while the majority of patients are stillborn (stillbirth). The average survival by the age of patients with trisomy 13 is 2.5 days, while only one in 20 infants live longer than 6 months [3]. Usually, the non-interventional paradigm of providing supportive treatment has been recommended for trisomy 13 since the high mortality of the disorder, the severe intellectual disability in those that survive beyond 1 year of age, and the lack of a cure. However, acceptance of this paradigm is not universal because survival beyond infancy is possible, particularly in those who receive intensive treatment. In a Canadian cohort study, 29 of the 41 children who underwent surgeries ranging survived for at least 1 year after the first surgery [14], [15].

To the best of our knowledge, this is the first case series study of trisomy 13 in Indonesia. Our study observed NTDs surgery, such as cele resection, to correct encephalocele, meningioencephalocele, or myelomeningocele. Despite intensive managements, including medications, Patau syndrome patients showed no significant improvement in survival. Since 
cardiopulmonary arrest was the cause-of-death in four out of five of our patients, we concluded that the major factors for long-term survival of patients with trisomy 13 are an active resuscitation that performed immediately after birth, as well as definitive surgical treatments when required, such as tracheotomy and closure of NTDs.

In conclusion, our study described a case series of five patients who were diagnosed with Patau syndrome at our center. The cases particularly focused on CNS malformations in patients with trisomy. Since definitive interventions are not yet available, it is natural for clinicians to focus on NTDs that are identified in trisomy 13 patients. Nonetheless, our data suggest that despite any neurosurgical interventions, patients with trisomy 13 still die at an early period in life. These indicate that the CNS malformations are indirectly responsible for mortality in patients during their early period in life; therefore, neurosurgical intervention should not be the initial priority. Our study suggests that the initial treatment of trisomy 13 patients in our center should be focused to treat or prevent any emerging respiratory failure.

\section{References}

1. Edwards JH, Harnden DG, Cameron AH, Crosse VM, Wolff OH A new trisomic syndrome. Lancet. 1960;1(7128):787-90. https:// doi.org/10.1016/s0140-6736(60)90675-9 PMid:13819419

2. Wyllie JP, Wright MJ, Burn J, Hunter S. Natural history trisomy 13. Arch Dis Child. 1994;71(4):343-5. https://doi.org/10.1136/ adc.71.4.343

PMid:7979530

3. Schinzel A. Catalogue of Unbalance Chromosome Aberration in Man. $2^{\text {nd }}$ ed. Beril, New York: Walter de Gryter; 2001. p. 505-10.

4. Springett A, Wellesley D, Greenlees R, Loane M, Addor MC, Arriola $L$, et al. Congenital anomalies associated with trisomy 18 or trisomy 13: A registry-based study in 16 European countries, 2000-2011. Am J Med Genet A. 2015;167A(12):3062-9. https:// doi.org/10.1002/ajmg.a.37355

PMid:26347425

5. Byrne J, Warburton D. Neural tube defects in spontaneous abortions. Am J Med Genet. 1986;25(2):327-33. https://doi. org/10.1002/ajmg.1320250219
PMid:3777029

6. Seller MJ. Neural tube defects, chromosome abnormalities and multiple closure sites for the human neura tube. Clin Dysmorphol. 1995;4(3):202-7. https://doi. org/10.1097/00019605-199507000-00002

PMid:7551155

7. Phadke SR, Thakur S. Prenatal diagnosis of iniencephaly and alobar holoprosen-cephaly with trisomy 13 mosaicism: A case report. Prenat Diagn. 2002;22(13):1240-1. https://doi. org/10.1002/pd.484

PMid:12478643

8. Halder A, Agarwal S, Pandey A. Iniencephaly and chromosome mosaicism: A report of two cases. Congenit Anom (Kyoto). 2005;45(3):102-5. https://doi. org/10.1111/j.1741-4520.2005.00076.x

PMid:16131369

9. Rodriguez JI, Garcia M, Morales C, Morillo A, Delicado A. Trisomy 13 syndrome and neural tube defects. Am J Med Genet. 1990;36(4):513-6. https://doi.org/10.1002/ajmg.1320360429 PMid:2202219

10. Vendola C, Canfield M, Daiger SP, Gambello M, Hashmi SS, King $\mathrm{T}$, et al. Survival of Texas infants born with trisomies 21, 18, and 13. Am J Med Genet A. 2010;152A(2):360-6. https://doi. org/10.1002/ajmg.a.33156

PMid:20082470

11. Petry P, Polli JB, Mattos VF, Rosa RC, Zen PR, Graziadio C et al. Clinical features and prognosis of a sample of patients with trisomy 13 (Patau syndrome) from Brazil. Am J Med Genet A. 2013;161A(6):1278-83. https://doi.org/10.1002/ajmg.a.35863 PMid:23613355

12. Peroos $\mathrm{S}$, Forsythe $\mathrm{E}$, Pugh JH, Arthur-Farraj P, Hodes $\mathrm{D}$. Longevity and Patau syndrome: What determines survival? BMJ Case Rep. 2012;2012:bcr0620114381. https://doi.org/10.1136/ bcr-06-2011-4381

PMid:23220825

13. Nelson KE, Rosella LC, Mahant S, Guttmann A. Survival and surgical interventions for children with trisomy 13 and 18. JAMA. 2016;316(4):420-8. https://doi.org/10.1001/jama.2016.9819 PMid:27458947

14. Kosho T, Nakamura T, Kawame H, Baba A, Tamura M, Fukushima Y. Neonatal management of trisomy 18: Clinical details of 24 patients receiving intensive treatment. Am J Med Genet A. 2006;140(9):937-44. https://doi.org/10.1002/ ajmg.a.31175 PMid: 16528744

15. Nelson KE, Hexem KR, Feudtner C. Inpatient hospital care of children with trisomy 13 and trisomy 18 in the United States. Pediatrics. 2012;129(5):869-76. https://doi.org/10.1542/ peds.2011-2139

PMid:22492767 